\title{
Autism, Queer Identity, And Applied Behavior Analysis: A Case Study In Multiple Minority Identity Development
}

Rachel Womack ( $\square$ rpwo222@uky.edu )

University of Kentucky https://orcid.org/0000-0001-6005-1166

Natalie D. Pope

University of Kentucky

Chelsea Gibbs

University of Kentucky

\section{Research Article}

Keywords: queer, ABA therapy, identity, autism, intersectionality

Posted Date: February 2nd, 2022

DOI: https://doi.org/10.21203/rs.3.rs-1244710/v1

License: (c) (1) This work is licensed under a Creative Commons Attribution 4.0 International License.

Read Full License 


\section{Abstract}

Despite an increased interest in identity development and expression at the intersection of queerness and disability, most existing literature fails to address the role of outside factors in influencing the process of navigating multiple identities. Participation in applied behavior analysis (ABA) therapy, a commonly used intervention for autistic individuals, is one such potential factor. This qualitative case study investigated the experience of identity expression and development in an autistic, queer-identified individual who received ABA therapy as a child. Analysis revealed four themes concerning the experience of identity development and expression in this autistic, queer individual: naming, masking, connecting, and developing. These themes are described in detail. Additionally, the Multidimensional Identity Model (MIM) was applied to the findings to help provide a theoretical framework for understanding the intersection of the participant's multiple identities throughout her life. Findings suggest that, over time, the participant spent time in each of the four options for identity expression outlined by the MIM. Additionally, relevant contextual factors in the participant's experience were found to include participating in ABA therapy, receiving a formal autism diagnosis, and finding community and connecting with like-minded others.

\section{Introduction}

Historically, gender and sexuality in the disabled population has been largely ignored, with disabled individuals being often, and incorrectly, regarded as inherently asexual [32,50]. This misguided assumption has led practitioners and researchers to overlook the rich, complex sexual and gender identities that many disabled individuals hold. In fact, a clear link exists between disabled and queer identity. A recent study found that queer people are significantly more likely to have a disability compared to the general population, with one in three lesbian and bisexual women identifying as disabled, as well as $39 \%$ of transgender individuals [30]. Further, other estimates put the percentage of autistic adolescents and adults who identify as queer anywhere from three to six times higher than within the neurotypical population $[15,49]$.

While identity development and expression at the intersection of queerness and disability have been given some attention in academic literature $[6,10]$ many studies fail to address the ways in which outside factors can further complicate the process of navigating and embracing these specific multiple minority identities. One such potential factor is participation in certain therapeutic interventions, such as applied behavior analysis (ABA) therapy [24]. This intervention was selected as a focus of this study due to its historical place as a commonly used therapy for autistic individuals. Additionally, studies specifically addressing identity development among queer autistic individuals are still lacking [27]. To help address these problems, this qualitative case study focuses on amplifying the voice of a queer, autistic selfadvocate who received ABA therapy as a child. In this paper, we explore this person's experience with identity development and expression over time, using the Multidimensional Identity Model [34] as theoretical lens for analysis.

\section{Review Of The Literature}


There are many parallels between the othering experienced by queer and disabled individuals, and the experiences and prejudices that shape their identity development and communication of that identity. The intersection of these two identities is complex, and it has been argued that neither queer theories nor disability theories have adequately accounted for the unique experiences of this population [e.g., 41]. Queer, disabled individuals must continuously contend with the oppressive forces of both ableism and heterosexism $[1,10,16]$. Because of challenges related to discrimination and prejudice based on disability status and gender identity, many queer, disabled individuals are forced to navigate identity development and expression in a world that does not readily accept who they are [14]. Additionally, the intersection of these two identities is further complicated by social pressures to perform certain sexual or gender roles. For example, Kourti and Macleod [20] found autistic identity impacts the way one thinks about and embraces sexuality and gender roles. For the female-identified autistic individuals in their study, traditional roles did not feel right to them, and they generally characterized their identity as fluid. However, participants often felt a need to adjust their relationship with sexuality and gender to disguise their autistic identity.

For disabled individuals of all sexual orientations and gender identities, and those with autism specifically, formal diagnosis can become a useful tool for identity development and understanding [38]. However, having an official diagnosis can also lead to therapies and services that may inhibit the continual process of identity exploration and may even cause harm to the person and their sense of self. One such therapeutic approach (i.e., ABA) is described below.

\section{Applied Behavior Analysis}

Applied behavior analysis (ABA), an intervention rooted in operant conditioning, is a therapeutic approach commonly used for autistic children. In the 1960s, Ole Ivar Lovaas (1927-2010) pioneered ABA as a therapy to help autistic individuals and their families understand and change undesirable behavior [42]. The therapy uses positive rewards to encourage desired behaviors and aversive stimuli to decrease undesirable behaviors [42]. ABA is typically used to reduce unwanted behaviors displayed by autistic children such as non-speaking communication, lack of eye contact, and repetitive movements (e.g., hand flapping, self-harm, and echolalia). This therapy is utilized with children as young as elementary school age and the treatment can be provided for up to forty hours per week [35]. ABA therapy has historically been considered the gold standard of therapeutic approaches for autistic individuals and has also been utilized with other populations including those with substance use disorders, brain injuries, and other mental health disorders [4]. Proponents of this approach describe ABA therapy as being effective in modifying a variety of behaviors and improving outcomes for autistic individuals [39, 48].

Despite evidence of the effectiveness of $A B A$, over the past decade, there has been increasing opposition to the methods and goals utilized by ABA therapists, particularly among autistic self-advocates. While some from the academic community have been critical of this therapy $[22,40]$, most of the opposition to ABA exists within popular media [9] and, even more so, within the autistic self-advocacy community via 
blogs, social media posts, and discussion boards [2, 19,23]. Common criticisms of ABA therapy proffered by autistic advocates include parent desires and preferences being prioritized over the emotional wellbeing of children [2], extinguishment of adaptive self-stimulatory behaviors which can be helpful to autistic people [25], and children being taught that their natural way of being is wrong and should be changed [12].

Recently, researchers who have examined the impact of ABA therapy on autistic individuals have also begun to voice their concerns. One study by Kupferstein [21] found that autistic children and adults who had participated in ABA therapy had about a $50 \%$ chance of experiencing post-traumatic stress symptoms. While there was no specific evidence that ABA therapy was the cause of the trauma symptoms, only $28 \%$ of autistic individuals who had not experienced ABA showed post-traumatic stress symptoms. In a qualitative study of experiences with ABA therapy for people with autism, McGill and Robinson [24] noted that the treatment was associated with a lack of self-agency, feelings of trauma and self-loathing, and a struggle to embrace autistic identity. Other authors, like [51] have gone so far as to call ABA therapy a "violation of the fundamental tenets of bioethics" (p. 1) that infringes on the autonomy of children and causes harm from a moral/ ethical perspective.

\section{Multidimensional Identity Model (Mim)}

Few theoretical frameworks account for the fluidity of identity development and many theories adopt a linear approach to development [33]. The Multidimensional Identity Model (MIM) [34] was developed out of recognition that viewing one's identities in a fragmented way, as opposed to through a holistic and fluid lens, could be unhelpful and even harmful to individuals who identify with multiple minority statuses. The MIM acknowledges that people embrace various aspects of their identities at different stages in life and offers four stages (or options) of identity development. The first two options focus on identifying with one aspect of self. Option 1 refers to an identity resolution state in which the individual identifies with one aspect of themselves in a passive, socially assigned fashion [33]. This option is the most clearly influenced by context, and the singularly chosen identity is determined by which is most visible to or valued by others at a given time.

Option 2, also identifying with one aspect of self, refers to an identity resolution state in which a person relates to one aspect of themselves in an active manner [33]. In this option, individuals make conscious choices about how they identify. Still, this choice in identity is shaped by the larger social and familial context; the choice to embrace one aspect of identity and reject others or embrace them to a lesser degree can be influenced by a desire to fit in or conform to surroundings. Option 3, identifying with multiple aspects of oneself in a segmented fashion, refers to an identity resolution state in which the individual accepts and embraces all aspects of their identity, but lives disconnected identities. People in this option do not typically exhibit their entire intersectional selves to the world. Instead, they present one aspect of their identity in certain situations and others in different settings separately. Finally, Option 4, identifying with combined aspects of one's identities, refers to an identity resolution state where individuals focus on 
the connection of their identities and embrace their intersectional selves. The choice to participate in these intersectional communities is a conscious one.

\section{Methods}

This paper describes a qualitative case study $[7,26]$ of one queer identified, autistic individual's experience with applied behavior analysis and the process of navigating identity development within the context of her multiple minority identities. The purpose of this study was to explore the experience of identity development and expression in a queer, autistic individual. Qualitative case study design was used, given its appropriateness to describe, explore and understand a present-day phenomenon in a realworld context [7, 52]. According to Merriam and Tisdell [26], a qualitative case study is "an intensive, holistic description and analysis of a single bounded unit" (p. 232). This paper draws on Stake's conceptualization of a qualitative case study whereby a case is viewed as a "bounded system" (p. 2). Given our research purpose, we also utilized an instrumental case study design whereby the issue(s), more than the case, was of primary interest [43]. In this project, the case (i.e., "Abigail") played a supportive role and facilitated our understanding of queer, autistic identity development as influenced by ABA therapy.

\section{Participant Recruitment}

Purposive sampling was used to locate a participant whose experiences were "information rich" as it related to the study purpose [26, p. 96]. The first author posted a brief description of the study and an invitation to potential participants in four online communities that were hosted through the Facebook platform. The invitation specified that the authors were recruiting an individual who identified as both autistic and queer and had received applied behavior analysis therapy in the past. Two of the communities served as networking and support sites for the queer community, while the other two served as support sites for autistic and neurodivergent individuals. The selected participant found the first author's post in one of the autistic community pages and reached out via Facebook Messenger. All subsequent communication and scheduling of interviews took place over email.

\section{Data Collection}

Over a three-month period, data were collected via three semi-structured interviews that occurred via video conferencing (i.e., Zoom). Video conferencing was selected as a suitable option for interviews given the geographic distance between the participant and research team (they lived in different states), and the participant and interviewer mutually agreed upon video conferencing as a suitable way to meet for the interviews. Interviews averaged forty minutes in length, and we designed an interview guide to elicit information about identity expression and development over time, factors influencing identity development and expression, the intersection of the participant's identities, and her experiences with $A B A$ therapy. Extant literature on queer and autistic identity development, $A B A$, and multidimensional identity 
theory $[13,16,33]$ informed our interview questions which included: How has your family shaped how you think about your disabled identity over time? Talk with me about conscious decisions you've made to embrace your disabled/ queer identity. How involved were you in the decision-making process in $A B A$ therapy? The participant was given a pseudonym (i.e., Abigail), and identifying information was altered to preserve confidentiality.

In consultation with the Office of Research Integrity at the participating university, it was determined that research governance was not necessary, due to the small number of research participants $(n=1)$ in this study. However, the study purpose was explained in detail and verbal/ written consent obtained from our participant. The data presented here are from three interviews with the participant that occurred over a period of two months. While the three authors collaborated on all phases of the present study, the first author took the lead in participant recruitment and data collection.

\section{Data Analysis}

The semi-structured interviews were digitally recorded and transcribed verbatim by the first author. The three members of the research team independently read through the transcripts and coded data segments having to do with the study purpose. Codes were developed inductively but were also informed by existing literature in ABA therapy and identity development [e.g., 14, 17, 45]. Patterns were independently identified by the research team, then compared, discussed, and agreed upon through regular meetings. During the entirety of data collection and analysis, an audit trail was kept on a shared

drive to track our progress, engage with data reflectively, and record methodological decisions $[8,46]$. The research team included individuals from social work and music therapy backgrounds. According to Barbour [3] colleagues from the same disciplines can "share the same blind spots" in terms of explicating and refining codes (p. 501); thus, investigator and interdisciplinary triangulation throughout all aspects of this study contributes to the rigor of our project [26]. Additionally, the first and third authors have experience working as supported employment professionals in the field of intellectual and developmental disability, which has afforded them the opportunity to interact regularly with a variety of autistic individuals, many of whom are also queer and are either currently receiving or have received ABA therapy.

\section{Participant Description}

This participant, Abigail, is a 39 year-old gender fluid individual of Jewish descent. Abigail's preferred pronouns are she/her. She is a college graduate with a degree in veterinary technology who works full time as a travelling veterinary technician. Abigail currently lives in a southeastern state with her husband and seven children, one of whom is her husband's niece. Her husband stays home with the children while she works. Her husband does not identify as a member of the queer community, but according to Abigail, he is likely autistic, though undiagnosed. She has been in a relationship with her husband since college and has never been in a relationship with a queer individual. Abigail is estranged from her two brothers and her parents. 


\section{Findings}

Four themes were identified concerning the experience of identity development and expression in this autistic, queer individual: naming, masking, connecting, \& developing. We describe and discuss these themes below, providing illustrative quotes from our interviews with Abigail.

\section{Naming}

Naming was an important aspect of Abigail's identity experiences and speaks to how the participant, and others, have described her identity. In childhood and adolescence, Abigail recalled hurtful, even traumatic, interactions with peers and family where she was bullied and called names by classmates. Although an awareness about her own sexual orientation did not solidify for Abigail until college, during middle school, peers had already labeled her as a lesbian.

Starting in 7th grade, I had a really good friend that, we were at this event, and I kept on going in and out of the bathroom to check on her because she was really upset. But they labeled me as a lesbian when I was 13, okay? That followed me until I graduated high school....I was considered an outcast.

After being mainstreamed in school (ie, being placed in a typical classroom as opposed to special education), Abigail "would get called the ' $r$ ' word a lot." She went on to say this about hurtful peer relationships during adolescence:

The way I was treated at school - it was just awful, and it followed me to religious school and the only way I had any break from it was at Girl Scouts. It was really bad. And when I told my parents about it, they told me I was lying, and they wouldn't do anything about it. So, I just had to suffer through this. They just didn't believe. They didn't want to go to the school and try to make people stop. I was either being bullied for [being a lesbian] or having a disability.

In childhood, Abigail was diagnosed as having Pervasive Developmental Delay (PDD) - NOS and ADHD and characterized as being "high functioning" (language she now rejects). Abigail's autistic identity did not develop until receiving a diagnosis at age 30 . Having the diagnosis helped her clarify and make sense of a lifetime of experiences that didn't quite fit under the ADHD and PDD umbrella. For Abigail, getting the diagnosis "was a relief" and helped solidify a clearer sense of self. Rather than person first language, Abigail uses identity first language. At the time of our interviews, Abigail described her current disabled identity as an autistic, neurodivergent, and hard of hearing person. When describing her disabled identity, Abigail pointed out that she is not part of the "capital D" deaf community, meaning that she does not consider herself to be a part of the deaf community that uses sign language and the culture that comes with that. She has not passively taken on a disabled identity, but consciously identifies as a disabled person. For Abigail, like many disabled self-advocates, there is power in claiming the word disability. She is proud to be a member of the disabled community. Abigail also considers herself to be neurodivergent. When asked what this aspect of her identity means to her, she stated: 
I would compare it to how different Windows and Macintosh is - how I would say neurotypicals run on Windows and... and neurodivergent people run on a MacOS. It's just a different way of being and different way of processing things.

As a child, Abigail's identity as a disabled person was minimized and stigmatized by her parents. As an adult however, Abigail draws strength and self-assurance from her autistic identity and dismisses people who attempt to reject this part of her. Although Abigail doesn't typically disclose to healthcare professionals her autism diagnosis (because it's not often relevant), she did tell a dermatologist who was treating her for skin issues connected to Polycystic Ovary Syndrome (PCOS). "PCOS is very common in the autistic community so I brought that up and the nurse asked me, 'Well, you don't look autistic.' And, I said, 'Well, what does autistic look like?"' Abigail went on to say, "The doctor came in like, 'You can go now.' [He] kicked the nurse out of the room." While Abigail found this dismissal of her autistic identity to be frustrating, she did not allow this interaction to tarnish the sense of confidence that she feels from embracing this part of her identity.

Interestingly, as a high school student, Abigail worked at a camp with autistic kids and was told, "you connect really well with them." Years later she remembered this camp experience and thought, "Well, that makes a lot of sense." As suggested by MIM, it seems she unconsciously connected with an identity and that identity may have been there before she was consciously aware of it. As a camp counselor working with autistic kids, Abigail was getting her first exposure to autism and autistic identity.

\section{Masking}

A second theme related to identity development and expression for Abigail, a queer, autistic individual, involves masking. This phrase was used by Abigail in our interviews to describe instances when she would hide her autism or when others would intentionally deny or conceal her identity (either as a disabled or queer person). For Abigail, masking started early on, and impacts how she engages with others even today:

When I was a kid and I was around my parents I was like, "Okay, how I am isn't good enough. I need to make sure I'm acting perfectly." But when I was away from them, I had to slowly learn how to be myself again.... I'm still working on it but there are times where I have to...'mask' in front of people I don't know. But when I'm at home, I'm completely myself. But when I'm out in the community I always have those thoughts.

When asked to say more about masking and what that looked like for her, Abigail said this:

Masking is when you...okay, the perfect example is when I was in high school. So, I would be with a group of people, and I would study them, and I would act like them so I wouldn't stand out. It's like acting in everyday life. Pretending to be someone you're not. 
From Abigail's perspective, having to participate in ABA therapy per her parents' mandate, influenced her perception of self as she viewed herself as less than, and flawed - "I was taught that the way you are isn't right and we need to change you." For instance, in therapy as a young child, Abigail got the message from both her therapist and parents, that how she learns (e.g., needing to get up and walk around) was "wrong." Because Abigail received punishment (e.g., withheld food, physically confined to a desk) for behaviors that were deemed unacceptable by her parents (e.g., failing to complete tasks), she would pretend to be someone she wasn't, mainly out of fear and desire to avoid mistreatment. But even after leaving home and starting a life independent of her parents, Abigail still questions her behavior and can sometimes feel uncertain with others:

"Is that wrong? Is that right? What if I made someone mad? Am I going to get punished for it?"....Whenever I feel like I've done something wrong I will apologize repeatedly until I'm told to stop because I'm afraid something's going to happen. It's definitely gotten better. My husband is definitely very...understanding [about] of a lot of things, but it was really hard... I couldn't trust anybody because the people I was supposed to trust put me through this horrific thing.

Abigail's parents initially hid the nature of her disability from her; Abigail only knew that she had a learning disability. Although Abigail was hard of hearing, her parents didn't want her to learn to sign: "I actually was taught in secret at school by a friend who taught me the signs because I couldn't communicate." Likewise, when Abigail attempted to come out to her parents about her sexual identity, the conversation with her mom went like this: "If hypothetically I was to tell you I was bi, what would you do?'... [my mom] said, 'I wouldn't want to know.' So, I'm like, okay then, that's that conversation. [I] never brought it up again." According to Abigail, this masking of her queer identity by her parents contributed to her own self-denial of this part of her identity.

Overall, Abigail described her home life growing up as one characterized by a culture of denial and secrecy around the nature of her disability; her parents often dismissed her bullying experiences at school and avoided talking about anything deemed as inappropriate or improper for Abigail or her family, like her gender identity and sexual orientation.

\section{Connecting}

One consequence of Abigail's parents masking her diagnosis and true self (i.e., sexuality, disability), and the message received that she must pretend to be someone else, is that Abigail wasn't able to connect with like-minded others until well into adulthood. After finally receiving an accurate diagnosis of autism at age 30, Abigail felt cheated. To her parents, Abigail said:

"You kept this information from me? I could have been connecting with other people"... Growing up I always felt different, I just didn't know why. I think all this time with me not knowing, that would have been gone. I would have been able to connect with other people and not feel so alone. 
Although it took many years for Abigail to feel solidly at home in a community, themes of belonging and connection with others made up much of the content of our conversations about identity development and expression. Soon after receiving an autism diagnosis, Abigail went online and found communities to connect with. Groups that she initially found were autism "martyr [parent] groups" - i.e., parents who aim to cure their child of autism or want to make their child appear more normal. Abigail had a friend "rescue" her from these groups and she quickly connected to autism self-advocates. She began developing an active online presence, critiquing abuse and pseudoscientific "treatments" for autism and cure culture in general. In fact, Abigail is quite well known in these circles because of her advocacy work, which has at times involved speaking out in public platforms: "Now in the autistic community, they say my name and they know who I am." This is in sharp contrast to Abigail's treatment in her youth when she was mistreated and silenced by her parents. Although she initially felt like, "no one is going to care what I have to say," she has since found her voice and become empowered to use that voice to help spare other autistic individuals from the mistreatment and isolation she endured as a child.

The acceptance and sense of belonging that Abigail experiences through online communities is in stark contrast to how she related to her parents: "I was always seeking their approval but whatever I did was just never good enough. Like I felt rejected. I felt like I didn't belong anywhere. I felt like a lost child." Yet about her online associations with other autistic people and parents of autistic children, Abigail said: "Connecting with these people all over the word and just connecting with other autistic people gives a stronger sense of identity and it's really...good for your mental health."

In college, as Abigail was just starting to explore her queer identity, she experienced newfound freedom to build relationships with lots of different kinds of people. When talking about going to a drag bar in college, Abigail said this - "I just felt like I fit in..." and compared it to her experience in childhood and adolescence: "I felt safe. I've never felt safe before." And while Abigail currently identifies as queer, she has not formally joined an online queer community and she doesn't feel the need to do so because the autistic community is so welcoming and inclusive. She also spoke of the closely intertwined nature of the queer and autistic communities- "Because I was around people who were more accepting and then I found out that the autistic community was like 70\% LGBT and I was like, wow, well that makes sense."

Connection and belonging were prominent themes as Abigail discussed her attitude towards child rearing and the culture of her own family (i.e., partner and children). All of Abigail's children are neurodiverse and she suspects her husband is on the autism spectrum as well. About her husband, Abigail said - "He is just the most accepting person that I will ever meet." Because all of Abigail's family members (i.e., partner and children) relate to each other so well, she never feels the need to mask at home.

\section{Developing}

Based on our three interviews with Abigail, a queer, autistic individual who participated in ABA therapy as a child, naming, masking, and connecting are central ideas that characterize her experience of identity development and expression. Additionally, developing is a fourth theme that we deemed relevant based 
on our analysis. For Abigail, some aspects of her identity are solid and well-defined, while other parts of her sense of self are still evolving.

With respect to her sexual orientation and gender identity, Abigail is still exploring what feels right to her. And while clearly identifying as queer, Abigail vacillates between classifying herself as nonbinary and gender non-conforming. She also goes back and forth between bisexual and pansexual. Interestingly, Abigail states that her sense of queer identity really has not changed much since she first began to explore that part of herself in college. However, part of the reason that Abigail still has not solidified her gender and sexuality identity may be because of the way their parents shut down any of these ideas during her adolescence and young adulthood. Any talk of non-normative sexual or gender identity was immediately suppressed which prevented and delayed the exploration of this part of her identity. Although called a lesbian by peers at school, Abigail recalls not even being sure what the term meant:

Honestly, back then I didn't even know what a lesbian was. I had to ask my parents what it was because I had no clue. I was sheltered. I had no idea...I do remember seeing this news clip....there was a lesbian wedding on and I'm like, "that's cool" and they quickly shut the TV off. [They said] "No, no, you can't marry a girl, only a boy!" I'm like, "okay..."

Abigail never dated any queer person, partly because her mother wouldn't let her; she was told that she needed to date a Jewish boy. Abigail admits, "...it took me a little bit longer to accept the LGBT [identity] because of everything that's been pounded into my head from when I was a kid."

Leaving home and gaining some independence from her parents while in college created a space for Abigail to begin exploring these aspects of her identity. Talking about when she started to wonder about her queer identity, Abigail shared: "When I left home, and I started making friends who come from different walks of life. That's when I started to wonder - after I left home." Abigail met her now-husband at age 19, while they were living in the same college dorm. The two started dating and soon married, all while Abigail was still making sense of her own gender and sexual identity. When asked about disclosing her queer identity to her husband, Abigail said: "It actually didn't happen for several years because that's when I was trying to figure things out on my own...I was in self-discovery while I was married." Although Abigail had never dated a queer person, she has no regrets: "I chose [the person] I wanted to. But then, due to outside forces, I was in self-denial for such a long time." According to Abigail, exploring and coming to terms with her queer identity made it much easier for her to discover and understand her autistic identity. She explained that the two communities are closely linked and being a part of the autistic ones create freedom to explore and expand her queer identity.

In closing, outside of being queer, some aspects of Abigail's gender and sexual identity, "[she is] still trying to figure...out." Certainly though, detaching from her family of origin and finding safety in community have helped Abigail feel safe to explore various aspects of her self-identity.

\section{Discussion}


The purpose of this study was to explore the experience of identity development and expression in a queer, autistic individual. Over time, Abigail's identity development and expression have been influenced by a variety of factors including her family, environment, and social connections. Analysis of the data revealed four primary themes that described the experience of identity development and expression in this autistic, queer individual: naming, masking, connecting, and developing. Each of these themes relates to the options for identity resolution posited by Reynolds and Pope [34] as part of their Multidimensional Identity Model (MIM). As told in our conversations with Abigail, her journey through identity development and expression included time spent in each of the four options outlined in this model [33, 34]. Through evaluation of interview transcripts, the authors of this study determined that Abigail's position within the four options at any given time appeared to be rooted in social context and in Abigail's conscious decisions to explore different aspects of her identity.

Though the options with the Multidimensional Identity Model are not linear, Abigail's time in Option 1, identifying with one aspect of self, primarily occurred in her childhood. For example, early in life Abigail knew that she had a learning disability and accepted this fact. This passive acceptance of this aspect of her identity was a result of her parents explaining to her that she did, indeed, have a learning disability. She felt no real connection to the disabled community at this time. Instead, she simply understood that she had a learning disability because this was how others had described her. This option relates best to the theme of naming, and the ways in which others described Abigail's identity had the most impact on her sense of self. However, simply being assigned an identity by others did not result in Abigail's conscious embracing of that part of herself. In contrast, when Abigail took an active role in naming aspects of her identity, it frequently led to her intentionally explore that part of her identity.

One of the first examples of Abigail exhibiting Option 2, active (rather than passive) identification with one aspect of self, can be seen in her childhood when she made the conscious decision to embrace her deaf identity. Though Abigail's parents tried to prevent her from learning sign language, something that would help her connect with the deaf community, her desire to belong led her to seek out someone to teach her sign language. This option can also be seen during Abigail's college years. While she did not necessarily make a conscious choice to stop exploring her disabled identity and seeking belonging in this area, she seems to have focused on her queer identity. Since she was surrounding by openminded individuals, exploring this part of herself was welcomed and even encouraged, creating an environment for her to develop this part of herself. For Abigail, this option for identity resolution was often associated with connecting and developing. It was the desire to be in relationship with others that led her to pursue learning sign language and integrating herself into the deaf and hard of hearing community. Additionally, time spent in this option tended to be simultaneous with periods of change, or development, in relation to her identity.

Option 3 was most clearly associated with the theme of masking. An example of Abigail in this stage, identifying with multiple aspects of oneself in a segmented fashion, is seen when she is both exploring her autistic identity and masking that identity in certain situations. Although she has fully embraced her autistic identity, and frequently engages with others who honor and celebrate that identity, she does 
sometimes attempt to hide her autism. This primarily occurs when Abigail is in a situation where she feels that she would need to explain her behavior or when she feels that it would be easier to present as neurotypical. There have also been times when Abigail identified with her queer identity in a segmented fashion. For example, when she was still in contact with her parents, Abigail refrained from discussing this aspect of herself. However, she readily expressed this part of herself while with her friends and college peers. For Abigail, this holding back of parts of herself could be attributed to her parents' denial of certain aspects of her identity, namely her sexual orientation and gender identity.

Lastly, the theme of connecting best fits with Abigail's expression of Option 4 in the MIM. For Abigail, she seems most comfortable in Option 4, identifying with combined aspects of her identities, while interacting with others in the online communities she has found. Though these groups (forums, Facebook groups, etc.) are intentionally geared towards facilitating connection between autistic individuals, Abigail reports that the intersection between the autistic and queer communities is so strong that she is fully able to embrace her queer identity in these spaces as well. These appear to be the places where Abigail is most able to be her authentic self. Additionally, her home environment also lends itself to Option 4. Abigail's husband and children support her journey towards self-discovery as it relates to her queer identity, and since all her family members are neurodiverse, home is also a safe space to fully express her autistic identity.

Though the model for identity development and expression discussed above considers the role of society and context as they relate to an individual's identity, it does not thoroughly explain the ways in which this occurs. In examining the data collected during this case study, we see several things that had a profound impact on Abigail's experience of identity development and expression. One of these is her participation in ABA therapy. Abigail spoke frequently of the emotional toll of engaging in this intervention, reporting continuous negative thought patterns related to the methods used during ABA. For example, she still struggles years later with questioning her behaviors, worrying if she'll anger someone and receiving some sort of punishment for her behavior. The potential for this type of long-term psychological harm was discussed by Sandoval-Norton and Shkedy [40], who suggested that adults could experience extended issues with self-esteem after receiving ABA therapy in their youth. For Abigail, she had difficulty coming to terms with the idea that people she trusted (i.e., her parents) would put her through such an experience. This is problematic since trust seems to be particularly important in relationships between autistic persons and their support system [36].

Perhaps most importantly, Abigail has had to overcome harmful perceptions of herself as an autistic person. ABA therapy and her interactions with her parents left Abigail feeling that "...the way you are isn't right and we need to change you." It is also important to note that, during Abigail's time in ABA therapy, she did not know that her "learning disability" was autism because she had not yet received a formal diagnosis. Receiving that diagnosis at the age of 30 was another pivotal experience for Abigail. Formal diagnosis provided a sense of clarity for Abigail and opened the door for her to begin connecting with others within the autistic community. While autistic people often feel disconnected from their communities, the importance of establishing a sense of belonging for these individuals cannot be 
understated [29, 31, 47]. In fact, connection to other autistic individuals provides access to a unique and vibrant autistic culture that has been often discussed in the literature [e.g., 5, 28]. Now that Abigail has is immersed in the autistic culture and community, she feels much more assured and comfortable in this aspect of her identity.

While Abigail explains that the queer and autistic communities are so intertwined that there is no need for her to seek out a queer community separately, she does note that, in college, it was ultimately her experience of spending time around other queer individuals that encouraged her to actively explore this part of her identity. Toft [44] notes that finding a community can create a particularly suitable atmosphere for coming out and embracing queer identity, especially for LGBT people with disabilities. Even more, finding a community of like-minded individuals contributes to a feeling of safety for the queer disabled individual who are thinking of coming out [44].

\section{Limitations}

While this study makes a meaningful contribution to the conversation surrounding identity development and expression and queer and autistic individuals, there are a handful of limitations that should be noted. First, as with all case studies, these findings are not generalizable in the conventional sense [18]. They are representative of the experiences of one individual- Abigail. However, it is important to note that generalization was not the goal of this research. As explained by Eisner [11], nongeneralizable studies are not inherently limited in contributing to the collective knowledge on a particular subject.

Additionally, this study attempts to examine and explain the complex phenomena of identity development and expression. In writing about these complexities, we have offered only one representation of the participant's experiences. Since this representation is based on the authors impressions of one set of conversations with the participant, it is possible that other aspects of the participant's experiences and story are unintentionally concealed [18]. Similarly, keeping in mind that the data used in this analysis were collected during three time-limited interviews, it is entirely possible that Abigail either elected not to share certain aspects of her experiences or did not think to include them during these conversations.

\section{Conclusion}

This qualitative case study explored the experiences of identity development and expression for Abigail, a queer, autistic individual who received ABA therapy as a child. Four themes - naming, masking, connecting, and developing - describe Abigail's experience and the MIM [33,34] offers as useful lens through which to frame these findings. Overall, Abigail appeared to spent experience each of the four options for identity resolution, as suggested by the MIM. Abigail's identity development option at any given time was influenced by a variety of factors. Relevant contextual factors in Abigail's experience include participation in ABA therapy, receiving a formal autism diagnosis, and finding community and connecting with like-minded others. 


\section{Statements And Declarations}

The authors declare that no funding sources including grants or other supports were used in the preparation of this manuscript.

The authors have no relevant conflicts of interest to disclose.

The Institutional Review Board at the University of Kentucky determined that this case study was exempt from IRB approval. Informed consent for participation and publication was obtained from the participant in this study.

All authors (Rachel Womack, Natalie Pope, and Chelsea Gibbs) contributed to the conception and design of this study. Rachel Womack was responsible for participant recruitments and collection of interview data. Chelsea Gibbs was responsible for transcription of interview data. All authors were involved in the analyses and of data and preparation of the manuscript.

\section{References}

1. Abrams EJ, Abes ES (2021) " It's finding peace in my body": Crip Theory to understand authenticity for a queer, disabled college student. Journal of College Student Development 62(3):261-275. https://doi.org/10.1353/csd.2021.0021

2. Autistic Science Person. (n.d.). Why ABA therapy is harmful to autistic people.Autistic Science Person.https://autisticscienceperson.com/why-aba-therapy-is-harmful-to-autistic-people/

3. Barbour RS (2014) Quality of data analysis. The SAGE Handbook of Qualitative Data Analysis,496510

4. Behavior Analyst Certification Board (BACB). (n.d.). About behavior analysis. https://www.bacb.com/about-behavior-analysis/

5. Burgess R (2020) Understanding the spectrum. Ought: The Journal of Autistic Culture 1(1):8

6. Campbell M (2017) Disabilities and sexual expression: A review of the literature. Sociology Compass 11(9):e12508

7. Creswell JW, Creswell JD (2017) Research design: Qualitative, quantitative, and mixed methods approaches. Sage Publications

8. Creswell JW, Miller DL (2000) Determining validity in qualitative inquiry. Theory Into Practice 39(3):124-130

9. DeVita-Raeburn E (2016) Is the most common therapy for autism cruel? The Atlantic.https://www.theatlantic.com/health/archive/2016/08/aba-autism-controversy/495272/

10. Drummond JD, Brotman S (2014) Intersecting and embodied identities: A queer woman's experience of disability and sexuality. Sex Disabil 32(4):533-549. https://doi.org/ 10.1007/s11195-014-9382-4

11. ̈̈»¿11. Eisner EW (1998) The enlightened eye: Qualitative inquiry and the enhancement of educational practice. Prentice-Hall, Upper Saddle River, NJ 
12. Fierce Autie (2020, January 19) What is ABA and my experience. Fierce Autie. https://www.fierceautie.com/2020/01/what-is-aba-and-my-experience.html

13. Gibson MF, Douglas P (2018) Disturbing behaviours: Ole Ivar Lovaas and the queer history of autism science. Catalyst: Feminism, Theory, Technoscience 4(2):1-28

14. Gobbo K, Shmulsky S (2016) Autistic identity development and postsecondary education.Disability Studies Quarterly, 36(3)

15. Hellemans H, Colson K, Verbraeken C, Vermeiren R, Deboutte D (2007) Sexual behavior in highfunctioning male adolescents and young adults with autism spectrum disorder. J Autism Dev Disord 37(2):260-269. https://doi.org/10.1007/s10803-006-0159-1

16. Henry WJ, Fuerth K, Figliozzi J (2010) Gay with a disability: A college student's multiple cultural journey.College Student Journal, 44(2)

17. Hillier A, Gallop N, Mendes E, Tellez D, Buckingham A, Nizami A, OToole D (2020) LGBTQ+ and autism spectrum disorder: Experiences and challenges. International Journal of Transgender Health 21(1):98-110. https://doi.org/10.1080/15532739.2019.1594484

18. Hodkinson P, Hodkinson H (2001, December) The strengths and limitations of case study research [paper presentation]. Learning and Skills Development Agency Conference, Cambridge, England

19. Kaylene (2019) Five important reasons even "new ABA" is problematic.Autistic Mama.https://autisticmama.com/even-new-aba-is-problematic/

20. Kourti M, MacLeod A (2019) "I don't feel like a gender, I feel like myself": Autistic individuals raised as girls exploring gender identity. Autism in Adulthood 1(1):52-59.

https://doi.org/10.1089/aut.2018.0001

21. Kupferstein H (2018) Evidence of increased PTSD symptoms in autistics exposed to applied behavior analysis. Advances in Autism 4(1):19-29

22. Journal of Autism and Developmental Disorders, 1-16. https://doi.org/10.1007/s10803-021-05137-y

23. Lynch CL (2019, March 28) Invisible abuse: ABA and the things only autistic people can see. Neuroclastic. https://neuroclastic.com/invisible-abuse-aba-and-the-things-only-autistic-people-cansee/

24. McGill O, Robinson A (2020) "Recalling hidden harms": autistic experiences of childhood applied behavioural analysis (ABA). Advances in Autism 7(4):269-282

25. Mel (2021) How does ABA actually impact autistic populations? Planet Neurodivergent.https://www.planetneurodivergent.com/how-does-aba-actually-impact-autisticpopulations/

26. Merriam SB, Tisdell EJ (2016) Qualitative research: A guide to design and implementation. John Wiley \& Sons

27. Miller RA, Nachman BR, Wynn RD (2020) "I feel like they are all interconnected": Understanding the identity management narratives of autistic LGBTQ college students. College Student Affairs Journal 38(1):1-15. https://doi.org/10.1353/csj.2020.0000 
28. Milton D (2017) "Imagining otherwise": Challenging dominant views regarding autism and how to help autistic people.Careknowledge,1-10

29. Milton D, Sims T (2016) How is a sense of well-being and belonging constructed in the accounts of autistic adults? Disability \& Society 31(4):520-534.

https://doi.org/10.1080/09687599.2016.1186529

30. Movement Advancement Project (July 2019) LGBT people with disabilities. https://www.lgbtmap.org/lgbt-people-disabilities

31. Pesonen HV, Kontu EK, Pirttimaa RA (2015) Sense of belonging and life transitions for two females with Autism Spectrum Disorder in Finland. Journal of International Special Needs Education 18(2):73-86. https://doi.org/10.9782/2159-4341-18.2.73

32. Peta C, McKenzie J, Kathard H, Africa A (2017) We are not asexual beings: disabled women in Zimbabwe talk about their active sexuality. Sexuality Research and Social Policy 14(4):410-424. https://doi.org/10.1007/s13178-016-0266-5

33. Pope RL, Reynolds AL (2017) Multidimensional identity model revisited: Implications for student affairs. New Directions for Student Services 157:15-24

34. Reynolds AL, Pope RL (1991) The complexities of diversity: Exploring multiple oppressions. Journal of Counseling \& Development 70(1):174-180

35. Roane HS, Fisher WW, Carr JE (2016) Applied behavior analysis as treatment for autism spectrum disorder. J Pediatr 175:27-32

36. Robledo J, Donnellan AM (2016) Supportive relationships in autism spectrum disorder: Perspectives of individuals with ASD and supporters. Behav Sci 6(4):23

37. Rosqvist HB (2012) Practice, practice: notions of adaptation and normality among adults with Asperger Syndrome. Disability Studies Quarterly, 32(2) available at http://dsqsds.org/article/view/3191/3075 retrieved December 18, 2015. doi:http://dx.doi.org/10.18061/dsq.v32i2.3191

38. 38. Rubey R (2017) Privileging autistics of color: A human rights approach to applied behavior analysis $(A B A)$ therap. [Master's thesis]. University of San Francisco

39. Sambandam E, Rangaswami K, Thamizharasan S (2014) Efficacy of ABA programme for children with autism to improve general development, language and adaptive behaviour. Indian Journal of Positive Psychology 5(2):192

40. Sandoval-Norton AH, Shkedy G (2019) How much compliance is too much compliance: Is long-term ABA therapy abuse? Cogent Psychology 6(1):1641258. https://doi.org/10.1080/23311908.2019.1641258

41. Santinele Martino A (2017) Cripping sexualities: An analytic review of theoretical and empirical writing on the intersection of disabilities and sexualities. Sociology Compass 11(5):e12471. https://doi.org/ 10.1111/soc4.12471

42. Smith T, Eikeseth S (2011) O. Ivar Lovaas: Pioneer of applied behavior analysis and intervention for children with autism. J Autism Dev Disord 41(3):375-378. https://doi.org/ 10.1007/s10803-010- 
$1162-0$

43. Stake RE (1995) The art of case study research. Sage Publications

44. Toft $A$ (2020) Identity management and community belonging: The coming out careers of young disabled LGBT+ persons. Sex Cult 24(6):1893-1912

45. Toft A, Franklin A, Langley E (2019) Young disabled and LGBT+: negotiating identity. Journal of LGBT Youth 16(2):157-172

46. Tracy SJ (2010) Qualitative quality: Eight "big-tent" criteria for excellent qualitative research. Qualitative Inquiry 16(10):837-851

47. Turner M (2018) Inclusion and autism: Belonging. In A. Geurin, \& T. McMenamin (Eds.), Belonging: Rethinking inclusive practices to support well-being and identity (pp. 25-39). Brill Sense

48. Walsh MB (2011) The top 10 reasons children with autism deserve ABA. Behavior Analysis in Practice 4(1):72-79. https://doi.org/10.1007/BF03391777

49. Nature Communications, 11(1), 1-12

50 . Whitney $C$ (2006) Intersections in identity-identity development among queer women with disabilities. Sex Disabil 24(1):39-52. https://doi.org/10.1007/s11195-005-9002-4

51. Wilkenfeld DA, McCarthy AM (2020) Ethical concerns with applied behavior analysis for autism spectrum" disorder". Kennedy Inst Ethics J 30(1):31-69

52. Yin RK (2002) Case study research: Design and methods, vol 5. Sage Publications 